Cite as:

Troop, N.A. (2016). The effect of current and anticipated body pride and shame on dietary restraint and caloric intake. Appetite, 96, 375-382.

\title{
The effect of current and anticipated body pride and shame on dietary restraint and caloric intake
}

\author{
Nicholas A. Troop \\ Department of Psychology, University of Hertfordshire, UK
}

Address for correspondence:

Dr Nicholas Troop, Department of Psychology, University of Hertfordshire, College Lane, Hatfield, Herts AL10 9AB, U.K. Email n.a.troop@herts.ac.uk 


\begin{abstract}
Studies have established a link between body shame and eating disorder symptoms and behaviours. However, few have differentiated current feelings of body shame from those anticipated with weight change and none has examined the effects of these on subsequent eating behaviour. In this paper, a measure of body pride and shame was developed (Study 1) for the purposes of using it in a subsequent longitudinal study (Study 2). Two hundred and forty two women were recruited from a university and the general population and participated in Study 1, completing the Body Pride and Shame (BPS) scale either online or offline, as well as a number of validating measures. In Study 2, 40 female students completed the BPS, as well as a measure of dietary restraint, and subsequently recorded their dietary intake every day for the next seven days. Study 1 identified and validated subscales of current body pride/shame as well as pride/shame that is anticipated were the individual to gain weight or lose weight. In Study 2, over and above levels of dietary restraint, current feelings of body shame predicted eating more calories over the next 7 days while the anticipation of shame with weight gain predicted eating fewer calories. Although previous research has only measured current feelings of body shame, the present study showed that anticipated shame also impacts on subsequent behaviour. Interventions that regulate anticipated as well as current emotions, and that do not merely challenge cognitions, may be important in changing eating behaviour.
\end{abstract}

Keywords: shame, body shame, eating, caloric intake, dietary restraint 


\section{Introduction}

Shame is a social emotion that involves the perception that one is judged by some real or imagined observer that one is flawed, inadequate or an object of disgust (Gilbert, 1992, 1998; Goss \& Allan, 2009; Miller, 1997; Power \& Dalgleish, 1997). A number of studies have shown that shame is related to eating pathology in clinical and non-clinical samples (Ferreira, Matos, Duarte, \& Pinto-Gouvei, 2015; Frank, 1991; Gee \& Troop, 2003; Grabhorn, Stenner, Stangier, \& Kaufhold, 2006; Kelly, Carter, \& Borairi, 2014; Masheb \& Brondolo, 1999; Murray, Waller \& Legg, 2000; Sanftner \& Crowther, 1998; Sanftner, Barlow, Marschall \& Tangney, 1995; Skårerud, 2007; Troop, Allan, Serpell \& Treasure, 2008; Swan \& Andrews, 2003; for a review see Goss \& Allan, 2009). Though a feature of psychopathology in general (Kim, Thibodeau \& Jorgensen, 2011), shame is predictive of eating pathology even controlling for depressive symptoms (Gee \& Troop, 2003; Troop et al., 2008).

Attention has recently turned towards examining the effect of body shame (as opposed to general shame) on eating pathology (Andrews, 1997; Rørtveit, Åström \& Severinsson, 2009; Slater \& Tiggemann, 2010). Though some studies have used a composite measure that includes body shame, behavioural shame and characterological shame (e.g. Sweetingham \& Waller, 2008; Keith, Gillanders \& Simpson, 2009), those that measure body shame separately generally find that it is a stronger predictor of eating pathology than is general shame (Burney \& Irwin, 2000) or that it is independently predictive (Doran \& Lewis, 2011).

Troop and colleagues (Troop, Sotrilli, Serpell and Treasure, 2006; Troop \& Redshaw, 2012), however, have argued that previous studies have been limited by measuring only shame that is currently experienced. Miller (1997) argues that shame is both punishing and prohibiting. While, if we experience shame, we may change our behaviour in order to escape this aversive 
state, we may also modify our behaviour in order to avoid feeling shame in the first place. One may, for example, attempt to lose weight if one feels ashamed of one's current body size while, if one feels that to gain weight would be shameful, then one may engage in preventive dieting rather than weight loss dieting (Russell, 1995).

Anticipated emotions in general have been shown to be an important predictor of health behaviours (Rivis, Sheeran \& Armitage, 2009). That is, the anticipation of how one will feel once a behaviour has been performed (or not performed) plays a role in the likelihood of engaging in a particular behaviour. In relation to the Theory of Planned Behaviour (Ajzen, 1991), this is often conceptualised as anticipated regret (if the health protective behaviour is not performed) and anticipated relief (if the behaviour is performed) (Rivis et al., 2009). Studies on the allocation of effort towards multiple goals (Louro, Pieters, \& Zeelenberg, 2007) have also shown that simply the anticipation of feeling positive or negative can influence engaging in a range of health behaviours such as attending screening, adhering to medication, quitting smoking, increasing physical activity and weight loss (Nelissen, de Vet \& Zeelenberg, 2011). In other words, goal directed behaviour is influenced by how people think they will feel rather than by how they currently feel (Brown \& McConnell, 2011).

To our knowledge, no study on current and anticipated body shame has examined its association with eating behaviours although two studies are of relevance. In a cross-sectional study of 214 non-clinical women and 224 women with a history of eating disorders, Troop et al. (2006) developed the Bodily Shame Scale (BSS). The BSS included scales measuring current body shame (the shame that is experienced in relation to one's current body size) and anticipated body shame (shame that is anticipated if one were to gain weight). Broadly speaking, in a non-clinical sample of women, current and anticipated body shame predicted 
fear of weight gain and restrictive efforts to reduce weight. This was also true in women with a history of eating disorders although current body shame also predicted bulimic behaviours (specifically binge eating and laxative abuse). A 2.5 year longitudinal study of 55 women with a history of eating disorders also showed that, while current body shame predicted an increase in the degree of underweight and misperception of body size, anticipated body shame predicted an increase in fear of weight gain (Troop \& Redshaw, 2012). Though relevant to the current research question, these studies explored eating disorder symptoms rather than normal eating behaviours.

Furthermore, while the inclusion of future oriented body shame has greater predictive value over some symptoms than a measure of currently experienced body shame, the BSS (Troop et al., 2006) has a number of limitations. Firstly, it measures only body shame; the possible influence of body pride cannot be determined. In addition, anticipated body shame in the BSS concerns only the feelings associated with imagined weight gain. Anticipated feelings in relation to weight loss are not considered. It may be, for example, that the anticipation of pride with weight loss has a different (or additional) effect from the anticipation of shame with weight gain.

The aim of this paper, therefore, is to examine the role of body pride as well as body shame in relation to current weight, imagined weight gain and imagined weight loss in predicting eating (specifically caloric intake). However, in order to achieve this, since no body pride/shame questionnaire currently exists that can measure this, a measure of body pride and shame is developed (Study 1) specifically for use in a prospective study (Study 2) to evaluate the roles of current and anticipated body pride and shame in predicting caloric intake over a period of seven days. 
On the basis of Miller's (1997) description of shame being both punishing and prohibiting, and Troop et al.'s (2006) cross-sectional findings in non-clinical women, it is hypothesised that current body shame and anticipated shame (with imagined weight gain) will predict consuming fewer calories over the next week. No specific prediction is made with respect to anticipated pride (with weight loss).

\section{Study 1: Preliminary development and validation of the Body Pride and Shame Scale}

\section{Materials and Methods}

\section{Ethics}

Ethical approval was obtained from the relevant university Ethics Committee.

\section{Participants}

Two separate samples were recruited: Sample $1(n=125)$ was an opportunistic sample of female participants recruited online; Sample $2(n=117)$ was an opportunistic sample recruited via snowballing through female students completing paper and pencil measures. Both samples completed the Body Pride and Shame scale (BPS) but Sample 1 also completed a number of questionnaires to validate this measure. Inclusion criteria were being female and over 18 years of age. There were no exclusion criteria.

Participants were all female with a mean age of 23.4 (7.4) years and mean BMI of 23.4 (4.2) $\mathrm{kg} / \mathrm{m}^{2}$. They were mostly white (white $64 \%$, Asian $12 \%$, Black $15 \%$, other $9 \%$ ), single 
(single 54\%, married/cohabiting 44\%, divorced 3\%) and were students (student $88 \%$, employed $10 \%$, unemployed $2 \%$ ).

\section{Measures}

The Body Pride and Shame Scale is a 30-item questionnaire developed for the purpose of this study. Items were derived in part from an existing questionnaire, the Bodily Shame Scale (BSS: Troop et al., 2006). This is an 11-item questionnaire that measures the feelings, thoughts and behaviours that relate to the experience of shame directed towards the body. It considers shame relating to currently perceived body size as well as shame that is anticipated should the individual gain weight (current and anticipated body shame respectively). However, to address the limitations of the BSS described in the Introduction, items were added or modified to (1) measure pride as well as shame and (2) to reflect these emotions in relation to weight loss as well as to weight gain and current weight. Thus, five shame items and five pride items measuring behavioural, affective and attitudinal aspects were included to which participants indicated the degree to which they experienced (or anticipated they would experience) these emotions in relation to current body weight, imagined weight gain and imagined weight loss. The 10 items in each of these three sections were identical except insofar as they reflected different temporal perspectives (current versus anticipated). There are 30 items in total and each is scored on a 10-point Likert scale with response options ranging from "not at all true of me" to "completely true of me".

The following measures were used for validation:

Eating disorder symptoms: The Short Evaluation for Eating Disorders (SEED: Bauer et al., 2005 ) is a brief self-report questionnaire measuring behavioural and attitudinal symptoms of 
eating disorders. Specifically, these are the degree of underweight (AN1), fear of weight gain (AN2), the misperception of body size (AN3), frequency of binge eating (BN1), frequency of compensatory behaviours (BN2: vomiting and laxative abuse) and over-concern with body weight and shape (BN3). The SEED has shown validity (Bauer et al., 2005) although the version used here was modified slightly from the original to include the definition of binge eating (i.e. 'consuming a large amount of food, that the average person would consider unusually large, and in a short period of time (less than 2 hours) where you also experience a sense of losing control over your eating') to improve reliability of reporting its frequency.

Mood: The Depression-Happiness Scale (DHS: McGreal \& Joseph, 1993) is a 25-tem questionnaire in which respondents indicate the degree to which they agree with statements concerning how they have felt over the last seven days. Items are rated on a 4-point Likert scale ("Never" to "Often"). The DHS is a bi-directional scale with lower scores indicating greater sadness and higher scores indicate greater happiness.

Body checking: The Body Checking Questionnaire (Reas, Whisenhunt, Netemeyer \& Williamson, 2002) is a 23-item measure of the frequency with which participants engage in body checking behaviours in relation to their overall appearance, specific body parts and idiosyncratic checking behaviours. Items are scored on a 5-point scale ranging from never to nearly always and higher scores indicate more frequent checking.

General shame and pride: The Test of Self-Conscious Affect (Tangney, Wagner, \& Granzow, 1989) is a scenario-based measure in which participants are asked to rate the likelihood of responding in each of a number of ways to 15 common everyday situations. 
Items are rated on a 5-point Likert scale from 1 to 5 and sub-scales include proneness to shame, proneness to guilt, alpha pride (pride in self) and beta-pride (pride in behaviours)

\section{Data analysis}

Data were analysed using the statistical package SPSS 22 (SPSS Inc., Chicago, IL, USA). Principal components analysis was carried out and the number of factors identified by a combination of Eigen-values $>1$ and examination of the Scree plot, as well as a consideration of items loading on each factor. Factors were rotated using oblique rotation in the expectation of correlated factors and items were retained where they loaded at least $+/-.40$ on only one factor.

\section{Results and Discussion}

\section{Principal components analysis of the Body Pride and Shame Scale}

Bartlett's Test of Sphericity was $2616.04(\mathrm{p}<.05)$ indicating that correlations were non-zero and $\mathrm{KMO}=.87$ indicating that the sample size was sufficient. Therefore it was appropriate to proceed.

Principal Components Analysis gave five factors with Eigen values $>1$ although the Scree plot clearly showed four factors above the elbow (see Figure 1). However, when the 4-factor solution was explored using oblique rotation, the fourth factor was trivial: although two items on this fourth factor loaded above .40 (.44 and 47$)$, one of these loaded more strongly on another factor. No other items loaded $>.36$ on Factor 4 and so a 3 -factor solution was explored (see Table 1). 


\section{$\underline{\text { Table } 1 \text { about here }}$}

The 3-factor solution accounted for a total of $58.1 \%$ of the variance. Following oblique rotation, Factor 1 contained all the items relating to shame and pride in relation to imagined weight gain, Factor 2 contained all the items relating to shame and pride in relation to imagined weight loss and Factor 3 contained all the items relating to shame and pride in relation to current body size. Items in Factors 1 and 2 loaded clearly onto the relevant factors with no cross-loadings. In Factor 3, however, item 5 also loaded above .40 on Factor 1 and item 7 fell just short of the .40 cut-off (i.e. .37). However, in both cases, items loaded more highly onto Factor 3 than any other factor so, given the preliminary and exploratory nature of this measure, and the fact that all factors were clearly identifiable in relation to expected item-loadings, it was decided to retain these items on Factor 3. Although five items had Communalities just below .5 (between .31 and .46 ) mean Communality was .66 which suggests a 3-factor solution is sufficient for these data.

In Factors 1 and 2, shame items loaded positively while pride items loaded negatively. In Factor 3, this was reversed with pride items loading positively and shame items loading negatively. For consistency, all factors were coded so that high scores indicated greater body shame and low scores indicated greater body pride. Factors 1, 2 and 3 were labelled anticipated body pride and shame with imagined weight gain (BPS-gain), anticipated body pride and shame with imagined weight loss (BPS-loss) and current body pride and shame (BPS-current). Means, intercorrelations and internal consistencies for the three factors are presented in Table 2. Intercorrelations were significant though small-to-moderate and internal consistencies were high. Furthermore, scores for all three scales covered the full range of possible scores (1 to 10 ). 


\section{$\underline{\text { Table } 2 \text { about here }}$}

For the sample as a whole, BPS-Current scores and BPS-Gain scores were significantly and positively correlated with BMI $(\mathrm{r}=.40, \mathrm{p}<.001$ and $\mathrm{r}=.23, \mathrm{p}<.005$ respectively) while BPS-Loss scores were negatively correlated with BMI $(r=-.17, \mathrm{p}<.05)$. Age was correlated with all three BPS scales to a similar magnitude; this was non-significant for BPS-Current scores $(\mathrm{r}=.10, \mathrm{p}=.12)$ and BPS-Loss scores $(\mathrm{r}=-.11, \mathrm{p}=.08)$ but significant for BPS-Gain $(\mathrm{r}=.13, \mathrm{p}<.05)$

\section{Validation}

Means for validation measures and their correlations with BPS subscales are presented in Table 2 for the 125 participants (the online sample) who completed validation measures.

BPS-Current and BPS-Gain were positively correlated with TOSCA-shame while BPSCurrent and BPS-Loss were negatively correlated with TOSCA-pride (in particular alpha pride). No BPS scales correlated with TOSCA-guilt. Broadly, this pattern of correlations indicates that higher levels of body shame are associated with more general shame-proneness while higher levels of body pride are associated with more pride-proneness. It also indicates that the BPS scales are measuring something which is specific to shame rather than guilt. Higher scores on BPS-Current and BPS-Loss scales also correlated negatively with DHS scores (i.e. more current body pride and anticipated pride with weight loss are associated with greater happiness). 
In relation to eating- and body-related concerns, it is with BPS-Current and BPS-Gain that scales are significantly correlated. Specifically greater BPS-Current is related to more body checking (BCQ) and anorexic and bulimic symptoms while greater BPS-gain is related to more body checking (BCQ) and bulimic symptoms (BN1 and BN2). BPS-loss was unrelated to eating- and body-related concerns.

In summary, three bi-directional factors were identified measuring shame/pride in relation to current body size (BPS-current) and that anticipated were the individual to gain weight (BPSgain) or to lose weight (BPS-loss). Broadly speaking, the body pride/shame subscales were specifically correlated with general shame rather than guilt. Furthermore, the shame experienced in relation to current body size and anticipated in relation to imagined weight gain were correlated with eating disorder-related concerns, body checking and symptoms. Pride and shame anticipated in relation to imagined weight loss were largely unrelated to pathology.

\section{Study 2: Prospective study of body pride and shame on eating}

\section{Method}

\section{Ethics}

Ethical approval was obtained from the relevant university Ethics Committee.

\section{Participants}

Participants $(n=43)$ were recruited from psychology students at a University in the south east of England who participated for course credit in a study examining the effect of emotions 
on eating. Sample characteristics are given in Table 3. Participants were all female and were mostly white (white 60\%, Asian 35\%, Black 5\%) and single (single 40\%, married/cohabiting $30 \%$, in a relationship 30\%). Inclusion criteria were being female and over 18 years of age. There were no exclusion criteria.

\section{Table 3 about here}

Measures

Body pride and shame scale (BPS): The BPS is described in Study 1.

Caloric intake: Caloric intake was assessed by the use of daily food diaries in which participants recorded all food and drink consumed every day for seven days (including time of day, location, what was eaten/drunk and portion size). Calculation of the average number of calories consumed each day was made by the researcher entering the information obtained from the food diaries into the Food Frequency Questionnaire (FFQ; Cade \& Margetts, 1988). The FFQ is a measure of caloric intake and asks individuals to state how frequently they consume different food types rated on a 6-point Likert scale from "Rarely/Never" to '2 or more times a day". This is converted to average number of calories consumed daily on the basis of the nutritional content of average portion sizes (in this case, for women).

Dietary restraint: Dietary restraint was assessed using the 14-item Cognitive Restraint Scale (Westenhoefer, Stunkard \& Pudel, 1999) assessing both rigid and flexible dieting. For the purposes of the present study, because rigid and flexible dieting subscales correlated at .72 , an overall score was calculated by combining the two subscales in which higher scores mean more dietary restraint. 
Internal consistency for all multi-item scales was high (see Table 3).

\section{Procedure}

Participants were recruited individually and asked to complete a consent form, demographic sheet, the BPS and the measure of dietary restraint. They were then instructed in the use of the daily food diary and asked to complete one at the end of each day for the next 7 days. The food diaries were collected after 7 days and participants were debriefed and thanked.

\section{Data analysis}

Data were analysed using the statistical package SPSS 22 (SPSS Inc., Chicago, IL, USA). Thirty six participants are required for a regression analysis with $80 \%$ power to detect a moderate effect size in a 1 -tailed test with 4 predictors and $\alpha=.05$. Following correlational analysis, linear regression as carried out. Firstly, dietary restraint was regressed onto the three BPS subscales with variables entered using the Enter method. Subsequently, FFQ scores were regressed onto BPS subscales controlling for dietary restraint in a hierarchical regression with dietary restraint on Step 1 and the BPS subscales on Step 2 (again, with variables entered using the Enter method).

\section{Results and Discussion}

Of the 43 participants recruited, three did not complete the daily food diaries and so their data are excluded from all subsequent analyses.

Age and BMI were uncorrelated with BPS subscales (see Table 4). Dietary restraint was correlated positively with BPS-gain and negatively with BPS-loss while FFQ was correlated 
negatively with BPS-gain. Dietary restraint was also correlated negatively with FFQ. In other words, higher levels of dietary restraint was associated with more shame anticipated with weight gain and more pride anticipated with weight loss as well as eating fewer calories over the next seven days. More shame anticipated with weight gain was also correlated with eating fewer calories over the next seven days.

\section{$\underline{\text { Table } 4 \text { about here }}$}

Regressing dietary restraint onto BPS subscales showed that body pride and shame significantly predicted dietary restraint $\left(\mathrm{F}_{3,39}=4.07, \mathrm{p}<.05, \mathrm{R}^{2}=.238\right)$ with BPS-gain and BPS-loss being independently predictive. Specifically, BPS-gain predicted higher levels of dietary restraint $(\beta=.36, \mathrm{t}=2.20, \mathrm{p}<.05)$ while BPS-loss predicted lower levels $(\beta=-.35, \mathrm{t}$ $=-2.50, \mathrm{p}<.05)$. BPS-current was not significantly predictive $(\beta=.01, \mathrm{t}=.07, \mathrm{p}=.95)$. Coupled with the significant correlation between dietary restraint and subsequent caloric intake (FFQ scores), it is important to control for dietary restraint in examining the prediction of caloric intake (FFQ scores) from BPS scales

Table 5 gives the results for regressing FFQ total calorie scores onto dietary restraint in Step 1 and BPS scales in Step 2. Although dietary restraint was significantly predictive of FFQ total calorie scores (accounting for $12.1 \%$ of the variance in FFQ scores), BPS scales added significantly to the prediction (accounting for a further $17.6 \%$ of the variance in FFQ scores). In the final model, dietary restraint was no longer predictive and only BPS-current and BPSgain subscales were uniquely predictive of FFQ scores. Specifically, greater levels of current body shame at baseline predicted eating more calories over the next seven days while greater anticipation of shame with weight gain predicted eating fewer calories. 


\section{$\underline{\text { Table } 5 \text { about here }}$}

\section{General Discussion}

Since previous research on body shame has almost exclusively focused on feelings of shame that are currently held, the present study explored body pride and shame in relation to current weight as well as imagined weight loss or weight gain. In particular, we sought to examine how these temporal aspects of body shame related to dietary restraint and eating behaviour.

Greater levels of dietary restraint were predicted by anticipating more shame with weight gain and more pride with weight loss while current body shame was unrelated. More importantly, even after controlling for dietary restraint, body shame predicted a behavioural measure of caloric intake. Specifically, people who reported feeling more ashamed of their bodies went on to consume more calories in the next seven days while those who anticipated more shame should they gain weight went on to consume fewer calories.

While anticipated emotions have been shown to be important in relation to a range of health behaviours (e.g. Rivis et al., 2009; Louro et al., 2007), research on the impact of anticipated shame in relation to weight change has been surprisingly lacking. Clearly, while current feelings of body shame are important in relation to eating behaviour and pathology, so too is anticipated shame. Existing measures of shame (both general shame and body shame) refer only to current feelings and this lack has limited research in relation to psychopathology in general as well as to eating behaviour specifically (NB although the TOSCA [Tangney et al., 1992], a scenario-based measure of pride and shame, could be argued essentially to measure anticipated emotions, ratings are made in relation to specific events or situations that anyone 
might encounter at any time rather than in relation to a relatively stable change in circumstances that could potentially be avoided by taking preventive measures, as is the case in the present study).

\section{Strengths and limitations}

The sample size in Study 2 was not large although it was longitudinal and participants had to report their intake over repeated assessments (i.e. daily for seven days). Nevertheless, future research might usefully recruit a larger sample and follow participants over a longer period of time, not only to determine the longer term associations between body shame and eating but also whether this translates into weight change (or, indeed, changes in body pride and shame). Another limitation concerns the fact that measures were self-report and, although the measure of intake concerned actual behaviour, the translation of these into calories consumed involved entering information from the daily diaries into a questionnaire designed to calculate average daily caloric intake. Individualised assessments would have been preferable but were not feasible in the present study. Finally, other potential confounds were not included such as mood (anxiety, depression) which may have impacted on caloric intake. Eating pathology was also not assessed although it is likely that any participants with eating disorders would have high scores on dietary restraint and so, to some extent, are likely to have been controlled for in the regression analysis.

\section{Implications}

As already indicated in the Introduction, there has been a lack of research into anticipated shame and pride generally, as well as in relation to eating pathology or normal eating behaviour specifically. The results of this study are therefore novel. This paper took evidence concerning the role of anticipated emotions in Theory of Planned Behaviour and Multiple- 
Goal Pursuit frameworks to provide a rationale. However, the studies presented here do not provide a test of these theories, merely evidence that shame (which is not generally examined in these approaches) may be an important emotion to consider in future research as well as presenting a measure to do so.

Contrary to predictions, the study reported here found that those who feel more body shame eat more, not less, over the following week. Miller (1997) argues that current feelings of shame are punishing (i.e. aversive) and that people will engage in (or disengage from) a behaviour that will reduce this emotional state (i.e. in this case, consuming fewer calories). However, this was not the case here. It may be that, while current body shame is indeed punishing and aversive, it may be more an indicator of pathology rather than a motivation for actual behaviour change. Alternatively, eating more may have been an attempt to reduce feelings of shame (Allan \& Goss, 2012) which, since likely to be unsuccessful, may lead to further shame as a result (see Goss \& Allan, 2009, for a discussion of the shame-shame cycle).

On the other hand, as predicted, those who anticipate more body shame with weight gain do eat less over the following week which supports Miller's (1997) proposition that shame is prohibiting. In fact, the strength of the association between anticipated body shame and subsequent caloric intake is stronger than that between current body shame and intake.

Gilbert (1998) conceptualises shame as either internal (how one sees or judges the self; e.g. as worthless, flawed, morally defective or unattractive) or external (how one perceives that others see the self; e.g. as an object of scorn, ridicule and contempt). In a meta-analysis Kim et al. (2011) showed that external shame is more strongly related to psychopathology than is 
internal shame. The measure of body shame used here is a measure of internal shame which, according to Kim et al. (2011), is true of all existing measures of body shame. Whether external body shame would be more strongly predictive of eating behaviour and pathology is a question for future research following development of a measure that addresses this distinction explicitly.

Finally, since it was shame rather than dietary restraint that predicted caloric intake, efforts at preventing problematic eating behaviour might usefully focus on emotions rather than cognitions. For example, self-compassion (a way to regulate negative affect though selfkindness and common humanity: Neff, 2003) mediates the link between shame and eating pathology (Ferreira et al., 2015; Ferreira, Pinto-Gouveia \& Duarte, 2013) and eating disorder patients reporting early improvements in self-compassion during their treatment had faster reductions in shame (Kelly, Carter, \& Borairi, 2014). Such evidence has been taken to imply that interventions aimed at improving self-compassion would be useful in the treatment of eating disorders (e.g. Goss \& Allan, 2010; Gale, Gilbert, Read \& Goss, 2012). However, whether the same is true for mediating the effect of current and anticipated body shame in relation to caloric intake is a question for future research.

\section{Conclusion}

The studies reported here show that, while current feelings about one's body are important predictors of eating behaviour, so too are the feelings that are anticipated if one were to gain or lose weight. This seems like a fairly obvious statement to make. However, since currently existing measures fail to address this, the full picture of the impact of pride/shame experiences on eating (and, indeed, other relevant behaviours such as physical activity) may 
be theorised but not tested. While there are limitations in these studies, they do highlight a need to adopt such measures in order to understand and alter these behaviours. 
Highlights

- A measure of current and anticipated body pride and shame was developed

- We examined the effects of current and anticipated body pride and shame on eating

- $\quad$ Eating was measured using food diaries over a 7 day period

- Current feelings of body shame predicted eating more over the next 7 days

- Body shame anticipated with weight gain predicted eating less over the next 7 days 
Acknowledgement:

Thanks to Shetal Vajesang for assistance with data collection. 


\section{References}

Ajzen, I. (1991). The theory of planned behavior. Organizational Behavior and Human Decision Processes, 50, 179-211.

Allan, S., \& Goss, K. (2012). Shame and pride in eating disorders. In J. Fox \& K. Goss (Eds.), Eating and its disorders (pp. 154-166). Chichester, UK: Wiley.

Andrews, B. (1997). Bodily shame in relation to abuse in childhood and bulimia: a preliminary investigation. British Journal of Clinical Psychology, 36, 41-49.

Bauer, S., Winn, S., Schmidt, U.H., \& Kordy, H. (2005). Construction, scoring and validation of the short evaluation of eating disorders (SEED). European Eating Disorders Review, 13, $191-200$.

Brown, C.M. \& McConnell, A.R. (2011). Discrepancy-based and anticipated emotions in behavioral self-regulation. Emotion, 11, 1091-1095.

Burney, J., \& Irwin, H.J. (2000). Shame and guilt in women with eating disorder symptomatology. Journal of Clinical Psychology, 56, 51-61.

Cade, J. E. \& Margetts, B. M. (1988). Nutrient sources in the English diet: Quantitative data from three English towns. International Journal of Epidemiology, 17, 844-848.

Doran, J., \& Lewis, C. A. (2012). Components of shame and eating disturbance among clinical and non-clinical populations. European Eating Disorders Review, 20, 265-270. 
Ferreira, C., Matos, M., Duarte, C., \& Pinto-Gouveia, J. (2015). Shame memories and eating psychopathology: The buffering effect of self-compassion. European Eating Disorders Review, 22, 487-494. DOI: 10.1002/erv.2322

Ferreira, C., Pinto-Gouveia, J., \& Duarte, C. (2013). Self-compassion in the face of shame and body image dissatisfaction: Implications for eating disorders. Eating Behaviors, 14, $207-$ 210.

Frank, E.S. (1991). Shame and guilt in eating disorders. American Journal of Orthopsychiatry, 61, 303-306.

Gale, C., Gilbert, P., Read, N. \& Goss, K. (2012). An evaluation of the impact of introducing compassion focused therapy to a standard treatment programme for people with eating disorders. Clinical Psychology and Psychotherapy, 21, 1-12. DOI: 10.1002/cpp.1806

Gee, A., \& Troop, N.A. (2003). Shame, depressive symptoms and eating, weight and shape concerns in a non-clinical sample. Eating and Weight Disorders, 8, 72-75.

Gilbert, P. (1992). Depression: The evolution of powerlessness. Hove: LEA.

Gilbert, P. (1998). What is shame? Some core issues and controversies. In: P. Gilbert \& B. Andrews (Eds). Shame: Interpersonal behaviour, psychopathology and culture (pp. 3-38). New York: Oxford University Press. 
Goss, K., \& Allan, S. (2009). Shame, pride and eating disorders. Clinical Psychology and Psychotherapy, 16, 303-316.

Goss, K. \& S. Allan (2010). Compassion focused therapy for eating disorders. International Journal of Cognitive Therapy, 3, 141-158.

Grabhorn, R., Stenner, H., Stangier, U., \& Kaufhold, J. (2006). Social anxiety in anorexia and bulimia nervosa: The mediating role of shame. Clinical Psychology and Psychotherapy, 13, $12-19$.

Keith, L., Gillanders, D., \& Simpson, S. (2009). An exploration of the main sources of shame in an eating disordered population. Clinical Psychology and Psychotherapy, 16, 317-327.

Kelly, A.C., Carter, J.C., \& Borairi, S. (2014). Are improvements in shame and compassion early in eating disorders treatment associated with better patient outcomes? International Journal of Eating Disorders, 47, 54-64. DOI: 10.1002/eat.22196

Kim, S., Thibodeau, R., \& Jorgensen, R.S. (2011). Shame, guilt, and depressive symptoms: A meta-analytic review. Psychological Bulletin, 137, 68-96.

Louro, M.J., Pieters, R., \& Zeelenberg, M. (2007). Dynamics of multiple-goal pursuit. Journal of Personality and Social Psychology, 93, 174-193. 
Masheb, R.M., \& Brondolo, E. (1999). Shame and its psychopathologic correlates in two women's health problems. Binge eating disorder and vulvodynia. Eating and Weight Disorders, 4, 187-193.

McGreal, R., \& Joseph, S. (1993).The Depression-Happiness Scale. Psychological Reports, $73,1279-1282$.

Miller, W. (1997). The anatomy of disgust. Cambridge, MA: Harvard University Press.

Murray, C., Waller, G., \& Legg, C. (2000). Family dysfunction and bulimic psychopathology: The mediating role of shame. International Journal of Eating Disorders, $28,84-89$.

Neff, K. D. (2003). The development and validation of a scale to measure self-compassion. Self and Identity, 2(3), 223-250.

Nelissen, R.M.A., de Vet, E., \& Zeelenberg, M. (2011). Anticipated emotions and effort allocation in weight goals striving. British Journal of Health Psychology, 16, 201-212.

Power, M., \& Dagleish, T. (1997). Emotion: From order to disorder. Hove: Psychology Press.

Reas, D.L., Whisenhunt, B.L., Netemeyer, R. \& Williamson, D.A. (2002). Development of the Body Checking Questionnaire: A self-reprot measure of body checking behaviors. International Journal of Eating Disorders, 31, 324-333. DOI 10.1002/eat.10012 
Rivis, A., Sheeran, P., \& Armitage, C. J. (2009). Expanding the affective and normative components of the Theory of Planned Behavior: A meta-analysis of anticipated affect and moral norms. Journal of Applied Social Psychology, 39, 2985-3019.

Rørtveit, K., Åström, S., \& Severinsson, E. (2009). The feeling of being trapped in and ashamed of one's own body: A qualitative study of women who suffer from eating difficulties. International Journal of Mental Health Nursing, 18, 91-99.

Russell, G.F.M. (1995). Anorexia nervosa through time. In: G. Szmukler, C. Dare \& J.L. Treasure (Eds) Handbook of eating disorders: Theory, treatment and research (pp.5-17). Chichester: Wiley.

Sanftner, J.L., Barlow, D.H., Marschall, D.E., \& Tangney, J.P. (1995). The relation of shame and guilt to eating disorder symptomatology. Journal of Social and Clinical Psychology, 14, $315-324$.

Sanftner, J.L., \& Crowther, J.H. (1998). Variability in self-esteem, moods, shame, and guilt in women who binge. International Journal of Eating Disorders, 23, 391-397.

Skårerud, F. (2007). Shame and pride in anorexia nervosa: A qualitative descriptive study. European Eating Disorders Review, 15, 81-97. 
Slater, A., \& Tiggemann, M. (2010). Body image and disordered eating in adolescent girls and boys: A test of Objectification Theory. Sex Roles, 63, 42-49.

Swan, S., \& Andrews, B. (2003). The relationship between shame, eating disorders and disclosure in treatment. British Journal of Clinical Psychology, 42, 367-378.

Sweetingham, R., \& Waller, G. (2008). Childhood experiences of being bullied and teased in the eating disorders. European Eating Disorders Review, 16, 401-407.

Tangney, J.P., Wagner, P., \& Granzow, R. (1989). The test of self-conscious affect. George Mason University, Fairfax, VA

Troop, N.A., Allan, S., Serpell, L., \& Treasure, J.L. (2008). Shame in women with a history of eating disorders. European Eating Disorders Review, 16, 480-488.

Troop, N. A., \& Redshaw, C. (2012). General shame and Bodily Shame in Eating Disorders: A 2.5-Year Longitudinal Study. European Eating Disorders Review, 20, 373-378.

Troop, N.A., Sotrilli, S., Serpell, L., \& Treasure, J.L. (2006). Establishing a useful distinction between current and anticipated bodily shame in eating disorders. Eating and Weight Disorders, 11, 83-90.

Westenhoefer, J., Stunkard, A.J., \& Pudel, V. (1999). Validation of the flexible and rigid control dimensions of dietary restraint. International Journal of Eating Disorders, 26, 53-64. 
Table 1. Principal components analysis of the BPS (Study 1)

\begin{tabular}{|c|c|c|c|}
\hline & Factor 1 & Factor 2 & Factor 3 \\
\hline BPS1 & .33 & .05 & -.60 \\
\hline BPS2 & .13 & -.02 & .74 \\
\hline BPS3 & .32 & .15 & -.56 \\
\hline BPS4 & .05 & -.19 & .48 \\
\hline BPS5 & .41 & .14 & -.45 \\
\hline BPS6 & .08 & .15 & .96 \\
\hline BPS7 & .22 & .36 & -.37 \\
\hline BPS8 & .02 & .02 & .90 \\
\hline BPS9 & .25 & .24 & -.42 \\
\hline BPS10 & .05 & .12 & .94 \\
\hline BPS11 & .88 & -.01 & .04 \\
\hline BPS12 & -.55 & .21 & .10 \\
\hline BPS13 & .80 & -.06 & -.03 \\
\hline BPS14 & -.46 & .09 & .14 \\
\hline BPS15 & .85 & .05 & .13 \\
\hline BPS16 & -.64 & .29 & .07 \\
\hline BPS17 & .73 & .13 & .13 \\
\hline BPS18 & -.71 & .29 & .11 \\
\hline BPS19 & .81 & .10 & -.01 \\
\hline BPS20 & -.70 & .22 & .13 \\
\hline BPS21 & -.04 & .80 & .08 \\
\hline BPS22 & .20 & -.67 & .12 \\
\hline BPS23 & -.07 & .85 & .08 \\
\hline BPS24 & .02 & -.43 & .14 \\
\hline BPS25 & .13 & .73 & .02 \\
\hline BPS26 & .27 & -.69 & .09 \\
\hline BPS27 & .01 & .79 & .04 \\
\hline BPS28 & .16 & -.82 & -.02 \\
\hline BPS29 & .19 & .72 & -.02 \\
\hline BPS30 & .18 & -.78 & .07 \\
\hline Eigen values & 8.2 & 6.90 & 2.32 \\
\hline$\%$ variance & $27.4 \%$ & $23.0 \%$ & $7.7 \%$ \\
\hline
\end{tabular}


Table 2. Means, intercorrelations and internal reliabilities of the Bodily Pride and Shame $\underline{\text { Scale and validating measures (Study 1) }}$

\begin{tabular}{|c|c|c|c|c|c|c|}
\hline & Mean & S.D. & $\alpha$ & Current & Gain & Loss \\
\hline & & & & BPS & BPS & BPS \\
\hline \multicolumn{7}{|c|}{ Whole sample $(\mathrm{n}=242)$} \\
\hline Current BPS & 5.2 & 1.9 & .89 & & & \\
\hline Gain BPS & 7.6 & 2.0 & .91 & $.38 * * *$ & & \\
\hline Loss BPS & 3.8 & 2.2 & .90 & $.24 * * *$ & \multicolumn{2}{|l|}{$-.32 * * *$} \\
\hline \multicolumn{7}{|c|}{ Online sub-sample $(\mathrm{n}=$} \\
\hline \multicolumn{7}{|l|}{$\underline{125)}$} \\
\hline TOSCA-shame & 40.9 & 8.4 & .78 & $.37 * * *$ & $.21^{*}$ & .14 \\
\hline TOSCA-guilt & 54.0 & 7.8 & .78 & .09 & -.05 & .07 \\
\hline TOSCA-alpha pride & 19.6 & 3.3 & .65 & $-.21 *$ & -.02 & $-.19 *$ \\
\hline TOSCA-beta pride & 19.5 & 3.3 & .64 & $-.20 *$ & -.06 & -.18 \\
\hline DHS & 12.6 & 3.8 & .87 & $-.44 * * *$ & -.15 & $-.27 * *$ \\
\hline BCQ & 48.1 & 16.1 & .94 & $.44 * * *$ & $.45^{* * *}$ & -.14 \\
\hline $\mathrm{AN} 1^{1}$ & 0 & $0-4$ & N/A & -.12 & $-.39 * * *$ & $.41 * * *$ \\
\hline $\mathrm{AN} 2^{1}$ & 1 & $0-3$ & N/A & $.49 * * *$ & $.58 * * *$ & $-.29 * *$ \\
\hline $\mathrm{AN}^{1}$ & 0 & $0-2$ & N/A & -.08 & -.01 & .11 \\
\hline $\mathrm{BN} 1^{1}$ & 0 & $0-2$ & N/A & $.20 *$ & .06 & -.08 \\
\hline $\mathrm{BN} 2^{1}$ & 0 & $0-1$ & N/A & .13 & .04 & .10 \\
\hline $\mathrm{BN} 3^{1}$ & 1 & $0-3$ & N/A & $.43 * * *$ & $.34 * * *$ & .05 \\
\hline
\end{tabular}

${ }^{1}$ Symptom items for the SEED are rated on non-continuous scales and, therefore, medians and ranges are presented rather than means and standard deviations (response options for AN1 and BN1are 0, 2, 4 and 6; response options for all other SEED items are 0, 1, 2 and3). Correlations are therefore also Spearman's $\rho$ for these items

AN1 = degree of underweight; AN2 = fear of weight gain; AN3 = the misperception of body size; $\mathrm{BN} 1$ = frequency of binge eating; $\mathrm{BN} 2=$ frequency of compensatory behaviours (vomiting and laxative abuse); BN3 = over-concern with body weight and shape. 
Table 3. Sample characteristics for participants in Study 2

\begin{tabular}{lccc}
\hline & Mean & SD & Cronbach's $\alpha$ \\
\hline Age (years) & 22.2 & 5.1 & $\mathrm{n} / \mathrm{a}$ \\
BMI $\left(\mathrm{kg} / \mathrm{m}^{2}\right)$ & 21.5 & 3.5 & $\mathrm{n} / \mathrm{a}$ \\
FFQ total calories & 1887.5 & 575.9 & $\mathrm{n} / \mathrm{a}$ \\
Dietary restraint & 25.3 & 5.9 & .86 \\
BPS-Current & 4.9 & 1.5 & .83 \\
BPS-Gain & 7.1 & 1.6 & .84 \\
BPS-Loss & 4.0 & 1.7 & .90 \\
\hline
\end{tabular}

FFQ = Food Frequency Questionnaire; BPS-Current = shame/pride in relation to currently perceived body size; BPS-Gain = shame/pride anticipated were the individual to gain weight; BPS-Loss $=$ shame/pride anticipated were the individual to gain weight. 
Table 4. Inter-correlations of study variables in Study 2

\begin{tabular}{|c|c|c|c|c|c|c|}
\hline & Age & BMI & Dieting & FFQ & $\begin{array}{l}\text { BPS- } \\
\text { current }\end{array}$ & BPS-loss \\
\hline BMI & -.23 & & & & & \\
\hline Dietary restraint & -.12 & -.12 & & & & \\
\hline FFQ-total calories & .13 & .01 & $-.35^{*}$ & & & \\
\hline BPS-current & -.08 & .00 & .23 & .03 & & \\
\hline BPS-gain & -.11 & .13 & $.32 *$ & $-.38 *$ & $.51 * * *$ & \\
\hline BPS-loss & .06 & -.04 & $-.35^{*}$ & .15 & -.04 & .10 \\
\hline
\end{tabular}

FFQ = Food Frequency Questionnaire; BPS-Current = shame/pride in relation to currently perceived body size; BPS-Gain = shame/pride anticipated were the individual to gain weight; BPS-Loss $=$ shame/pride anticipated were the individual to gain weight. 
Table 5. Regressing caloric intake onto dietary restraint and body pride and shame (Study 2)

\begin{tabular}{|c|c|c|c|c|}
\hline & \multicolumn{2}{|l|}{ Step 1} & \multicolumn{2}{|c|}{ Step 2} \\
\hline & $\beta$ & p-value & $\beta$ & p-value \\
\hline Dietary restraint & -.35 & $<.05$ & -.22 & $=.19$ \\
\hline BPS-current & & & .34 & $<.05$ \\
\hline BPS-gain & & &.-.50 & $<.01$ \\
\hline BPS-loss & & & .14 & $=.40$ \\
\hline$\Delta$ F-value & $5.22 *$ & & $2.91 *$ & \\
\hline $\mathrm{df}$ & 1,38 & & 3,35 & \\
\hline$\Delta \mathrm{R}^{2}$ & .121 & & .176 & \\
\hline
\end{tabular}


Figure 1. Scree plot of the Principal Components Analysis of the Body Pride and Shame Scale (Study 1)

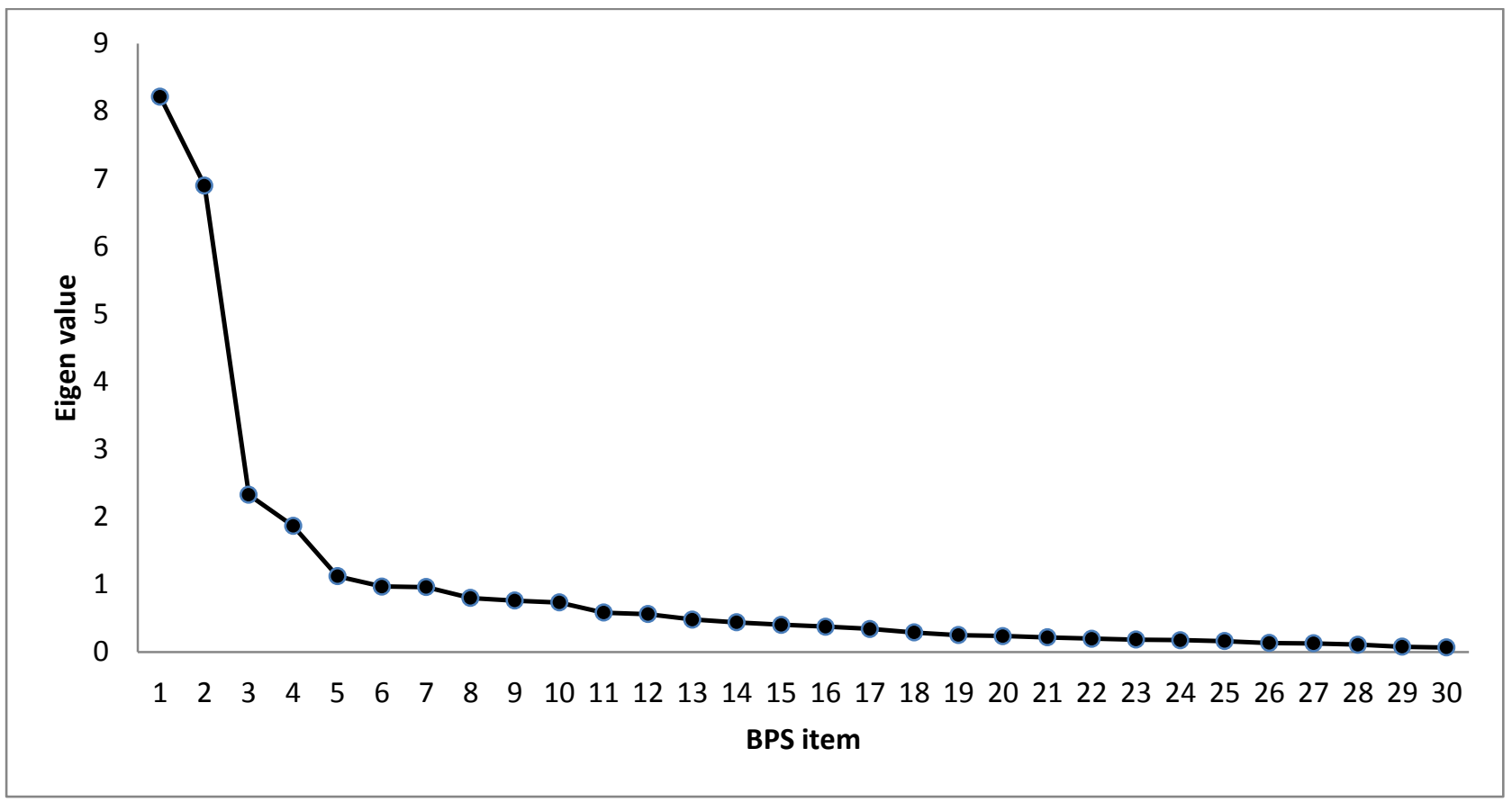




\section{Appendix 1: Bodily Pride and Shame Scale}

Below are a number of statements concerning the way that some people may feel about their bodies. Please indicate the degree to which each statement is true of you by circling the number in the right hand column that best matches the way you feel. Items are on a 10-point scale where " $1=$ not at all true of $m e$ " and " $10=$ completely true of me." There are no right or wrong answers so please try to be honest.

\begin{tabular}{|c|c|c|c|c|c|c|c|c|c|c|c|}
\hline \multicolumn{12}{|c|}{$\begin{array}{l}\text { Consider your body weight and shape as they are right now, please indicate the degree to which you agree with } \\
\text { each of the statements below (from } 1=\text { not at all true of me to } 10=\text { completely true of me) }\end{array}$} \\
\hline 1 & I am ashamed of my body & 1 & 2 & 3 & 4 & 5 & 6 & 7 & 8 & 9 & 10 \\
\hline 2 & I like showing off my body (e.g. on the beach, at the gym) & 1 & 2 & 3 & 4 & 5 & 6 & 7 & 8 & 9 & 10 \\
\hline 3 & I am embarrassed about my physical appearance & 1 & 2 & 3 & 4 & 5 & 6 & 7 & 8 & 9 & 10 \\
\hline 4 & I enjoy being complimented on the way I look & 1 & 2 & 3 & 4 & 5 & 6 & 7 & 8 & 9 & 10 \\
\hline 5 & I keep parts of my body covered up because I hate them so much & 1 & 2 & 3 & 4 & 5 & 6 & 7 & 8 & 9 & 10 \\
\hline 6 & I like the way my body looks & 1 & 2 & 3 & 4 & 5 & 6 & 7 & 8 & 9 & 10 \\
\hline 7 & I feel self-conscious if people comment on my appearance & 1 & 2 & 3 & 4 & 5 & 6 & 7 & 8 & 9 & 10 \\
\hline 8 & I am pleased with my physical appearance & 1 & 2 & 3 & 4 & 5 & 6 & 7 & 8 & 9 & 10 \\
\hline 9 & I avoid changing in communal changing areas (such as the gym) & 1 & 2 & 3 & 4 & 5 & 6 & 7 & 8 & 9 & 10 \\
\hline 10 & I am proud of the way my body looks & 1 & 2 & 3 & 4 & 5 & 6 & 7 & 8 & 9 & 10 \\
\hline
\end{tabular}

Imagine if you gained a significant amount of weight (say, a half to one stone), please indicate how far you agree with each of the statements below (from $1=$ not at all true of me to $10=$ completely true of me)

1 I would feel ashamed of my body

$\begin{array}{llllllllll}1 & 2 & 3 & 4 & 5 & 6 & 7 & 8 & 9 & 10\end{array}$

2 I would enjoy showing off my body (e.g. on the beach, at the gym)

$\begin{array}{lllllllllll}1 & 2 & 3 & 4 & 5 & 6 & 7 & 8 & 9 & 10\end{array}$

3 I would be embarrassed about my physical appearance

$\begin{array}{llllllllll}1 & 2 & 3 & 4 & 5 & 6 & 7 & 8 & 9 & 10\end{array}$

4 I would enjoy people commenting on the way I look

$\begin{array}{llllllllll}1 & 2 & 3 & 4 & 5 & 6 & 7 & 8 & 9 & 10\end{array}$

5 I would keep parts of my body covered up because I would hate them so

$\begin{array}{llllllllll}1 & 2 & 3 & 4 & 5 & 6 & 7 & 8 & 9 & 10\end{array}$ much

$6 \quad$ I would like the way my body looked

$\begin{array}{llllllllll}1 & 2 & 3 & 4 & 5 & 6 & 7 & 8 & 9 & 10\end{array}$

7 I would feel self-conscious if people commented on my appearance

$\begin{array}{lllllllllll}1 & 2 & 3 & 4 & 5 & 6 & 7 & 8 & 9 & 10\end{array}$

8 I would be pleased with my physical appearance

$\begin{array}{llllllllll}1 & 2 & 3 & 4 & 5 & 6 & 7 & 8 & 9 & 10\end{array}$

9 I would avoid changing in communal changing areas (e.g. the gym)

$\begin{array}{lllllllllll}1 & 2 & 3 & 4 & 5 & 6 & 7 & 8 & 9 & 10\end{array}$

10 I would feel proud of the way my body looks

$\begin{array}{llllllllll}1 & 2 & 3 & 4 & 5 & 6 & 7 & 8 & 9 & 10\end{array}$

Imagine if you lost a significant amount of weight (say, a half to one stone), please indicate how far you agree with each of the statements below (from $1=$ not at all true of me to $10=$ completely true of me)

1 I would feel ashamed of my body

$\begin{array}{llllllllll}1 & 2 & 3 & 4 & 5 & 6 & 7 & 8 & 9 & 10\end{array}$

2 I would enjoy showing off my body (e.g. on the beach, at the gym)

$\begin{array}{llllllllll}1 & 2 & 3 & 4 & 5 & 6 & 7 & 8 & 9 & 10\end{array}$

3 I would be embarrassed about my physical appearance

$\begin{array}{llllllllll}1 & 2 & 3 & 4 & 5 & 6 & 7 & 8 & 9 & 10\end{array}$

4 I would enjoy people commenting on the way I look

$\begin{array}{llllllllll}1 & 2 & 3 & 4 & 5 & 6 & 7 & 8 & 9 & 10\end{array}$

5 I would keep parts of my body covered up because I would hate them so

$\begin{array}{llllllllll}1 & 2 & 3 & 4 & 5 & 6 & 7 & 8 & 9 & 10\end{array}$ much

$6 \quad$ I would like the way my body looked

$\begin{array}{lllllllllll}1 & 2 & 3 & 4 & 5 & 6 & 7 & 8 & 9 & 10\end{array}$

7 I would feel self-conscious if people commented on my appearance

$\begin{array}{llllllllll}1 & 2 & 3 & 4 & 5 & 6 & 7 & 8 & 9 & 10\end{array}$

8 I would be pleased with my physical appearance

$\begin{array}{llllllllll}1 & 2 & 3 & 4 & 5 & 6 & 7 & 8 & 9 & 10\end{array}$

9 I would avoid changing in communal changing areas (e.g. the gym)

$\begin{array}{llllllllll}1 & 2 & 3 & 4 & 5 & 6 & 7 & 8 & 9 & 10\end{array}$

10 I would feel proud of the way my body looks

$\begin{array}{llllllllll}1 & 2 & 3 & 4 & 5 & 6 & 7 & 8 & 9 & 10\end{array}$ 